\title{
Flora Malesiana in the coming decade
}

\author{
M.C. Roos ${ }^{1}$, P. Hovenkamp ${ }^{1}$
}

Published on 30 October 2009

When the first Flora Malesiana Symposium was held in Leiden in 1989, a central theme was the urge to speed up the project. The measures taken at that symposium, such as the establishment of family teams, were successful and revitalized the Flora Malesiana project in a substantial way, although the allotment of the remaining families continues to be a problem.

However, by the end of the nineties, first signs of a loss of momentum appeared, which could be ascribed to a lack of concrete, more specifically, financial, incentives. A graph of the numbers of published species treatments since the late seventies shows that the progress has slowed down perceptibly since 2000 (Fig. 1). A closer look at the progress in this decade shows that some 800 species revisions have been published, including two large treatments (Table 1), compared to 2162 in the decade 1990-2000.

It has become obvious that if we want to finish the flora within a reasonable time span, the FM-community needs to adopt a flexible and pragmatic attitude: flexible in choice of formats and publication strategy, flexible with regard to standards of robustness of and confidence in the results, and pragmatic in the face of changing taxonomic views thanks to the quickly expanding field of molecular systematics.

To achieve this flexibility we will have to accept that information no longer has to be presented exclusively as printed matter, but

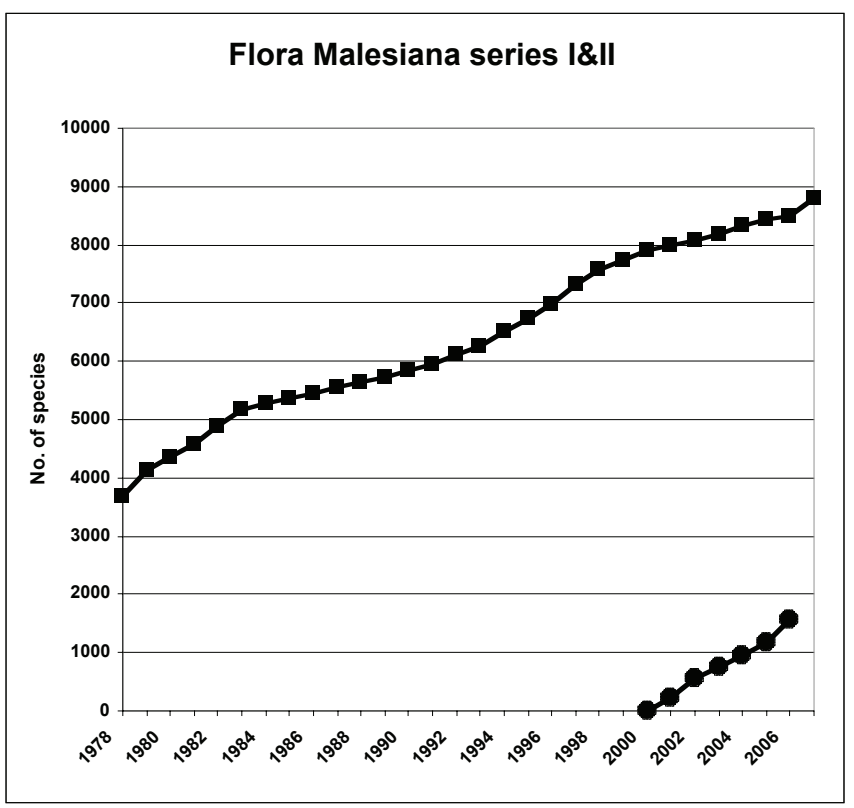

Fig. 1 The progress of Flora Malesiana since 1978 in terms of species treated in published instalments $\boldsymbol{\square}$ = printed instalments; $\boldsymbol{0}=$ species covered in the CD-ROM series on Orchidaceae.

1 National Herbarium of the Netherlands, Leiden University, P.O. Box 9514, 2300 RA Leiden, The Netherlands.
Table 1 Families and numbers of taxa revised in 2001-2007.

\begin{tabular}{lllrc}
\hline & Year & Taxon & species & Total \\
\hline Total 2001 & & & 7915 \\
& 2001 & Nepenthaceae & 83 & \\
& 2002 & Caryophyllaceae & 28 & \\
& 2002 & Cunoniaceae & 43 & \\
& 2002 & Potamogetonaceae & 14 & \\
& 2002 & Zosteraceae & 1 & \\
& 2002 & Cymodoceaceae & 5 & \\
& 2005 & Moraceae - Ficus & 367 & \\
& 2006 & Moraceae - other & 60 & \\
& 2007 & Apocynaceae: & 295 & \\
& $2001-2007$ & Rauvolfioideae/Apocynoideae & 896 & \multirow{2}{*}{8791} \\
\hline
\end{tabular}

may also take the form of interlinked databases, web-based revisions and keys or other electronic products. These means of presenting information have become widely accepted and we think they are the only way to go forward and ensure the future of FM. When we take this electronic information into account it becomes clear that despite the apparent slowdown in output, much relevant work is nevertheless being carried out, although part of it is not ready to be published in official instalments of FM, and some, perhaps, may never be.

To achieve the required pragmatism, we have to raise the question what the term 'Flora Malesiana' really stands for. Traditionally, it refers to the well-known product, i.e. THE series of FM instalments, the undisputed reference and primary source for all botanical surveys in the region, and for local or national floras and checklists. However, increasingly it has also come to refer to a network of taxonomic or regional floristic specialists who may form teams of varying composition for the revision of families. This network brings together the scientific developments in all aspects of Malesian plant diversity such as floristic inventories, ethnobotany, conservation and forest ecology, but also $\alpha$-taxonomy, cladistics and molecular phylogeny, historical biogeography and macro-ecology. Each of these fields generates data and information relevant for the Flora. Thus, the 'Flora Malesiana' now functions as a forum for the entire field of Malesian botany, facilitating the exchange of information and producing a variety of output formats ranging from identification lists and specimen databases to monographs, biodiversity and NTFP assessments and analyses of spatial patterns of biodiversity.

From this perspective, 'Flora Malesiana' as an umbrella for all kinds of taxonomic and systematic work, we can look the flora instalments as one extreme of a continuum; the other one being the specimens - not only the ones present in herbaria, but also those in the field, in (permanent) field plots etc. These two ends are related by a range of research activities. From the identification of specimens, through inventories and other biodiversity assessments, checklists, local floras to regional

() 2009 Nationaal Herbarium Nederland

You are free to share - to copy, distribute and transmit the work, under the following conditions:

Attribution: $\quad$ You must attribute the work in the manner specified by the author or licensor (but not in any way that suggests that they endorse you or your use of the work).

Non-commercial: $\quad$ You may not use this work for commercial purposes.

No derivative works: You may not alter, transform, or build upon this work.

For any reuse or distribution, you must make clear to others the license terms of this work, which can be found at http://creativecommons.org/licenses/by-nc-nd/3.0/legalcode. Any of the above conditions can be waived if you get permission from the copyright holder. Nothing in this license impairs or restricts the author's moral rights. 


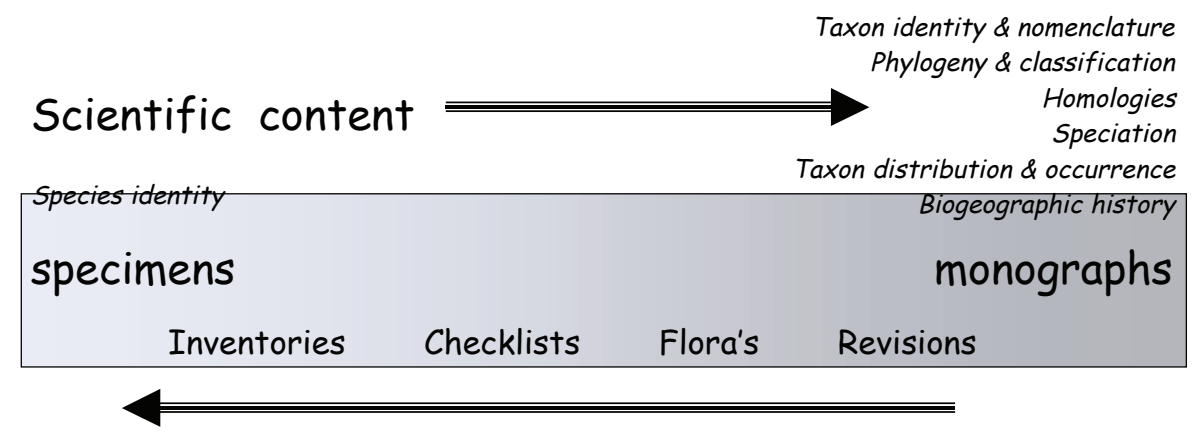

\section{Validation}

Fig. 2 The increasing scientific content of systematic products in the continuum from identified specimens to monographs and decreasing robustness of validation in the opposite direction.

revisions and global (total evidence) monographs, the amount of systematic information that is incorporated in the product increases. In the end, monographic treatments are the ultimate tool to validate the results in the reverse direction. While we continue to see the flora instalments as the ultimate end product, we have to acknowledge pragmatically that many intermediate products, such as databases or preliminary keys, are also part of the effort to identify and interpret the Malesian botanical diversity (Fig. 2, 3), and are worthy of wider dissemination.

To realize this vision fully, we again need a new momentum. We think that this now can be provided by the recent developments in ICT, which offer unsurpassed potential not only to collect and structure existing information, but also to exchange data and knowledge between different researchers. After the 2007 Leiden symposium we want to invigorate the Flora Malesiana Project, to let it truly enter the E-era and to turn it into one of the first running mega flora projects to become truly web-based and interactive. We consider this essential for the survival of FM. This effort calls for new milestones in terms of initiatives, products, cooperation, communication and training.

First of all, it requires that we acknowledge that all information is valuable. Of course, we should opt for a basic level of quality, but we have to keep in mind that 'Best' is the enemy of 'Good (enough)'. Too often, important pieces of knowledge have not been published because the author maintained unrealistically high scientific standards (in other words, for lack of confidence). It is urgently needed that we let our colleagues have access to available information and data, with an indication how well verified or preliminary they are. This will have enormous positive impact on the whole progress. In our vision of the future, we see

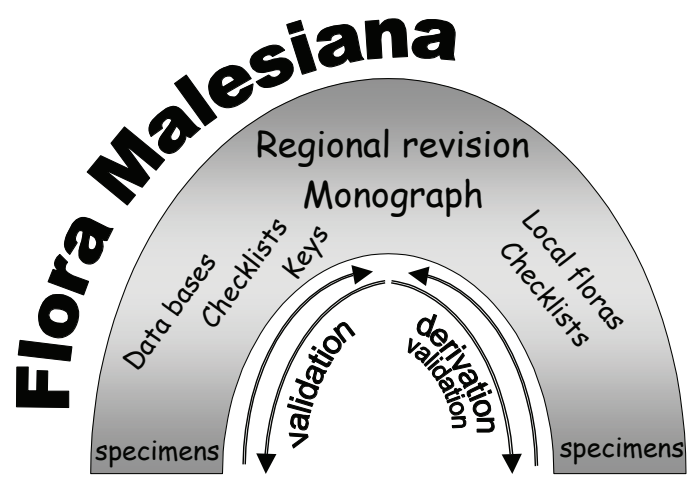

Fig. 3 The continuum of scientific activities and products covered by the Flora Malesiana project. All build up the whole of the FM information base, whereas the overall flora treatments can be used for validation of the information and to derive new products. a continuous process in which information is exchanged, with quality-control not only in the hand of the producer, but also in those of collaborators and colleagues, and with results that are constantly being scrutinized by both experts and users. What we need, accordingly, is a system that allows intense, instant communication between (international) colleagues, and that allows data and preliminary results to be shared, in a regulated manner, on an interactive forum. Participants in this process apply the taxonomic products and add their comments, opinions and suggestions. Together they will work towards a more robust end product, while keeping the information available for other lines of research. This process should apply to the production of databases, keys, species delimitations, classifications, drafts of revisions, partial revisions, etc.

It is encouraging to see that this vision is now no longer just wishful thinking, but that it is already a long way to being realized, with the development of web-based taxonomy tools like the EDIT scratchpads.

What is needed next to realize this vision more fully is a kind of front desk that acts as a clearing house for questions and demands from outside and inside the network, for information on funding possibilities and possibilities for cooperation. This front desk would also maintain and stimulate contacts and links with other international networks and organizations such as GBIF or EDIT. It would facilitate and regulate the access to any preliminary information by creating and maintaining an interactive platform, consisting of a community-based portal and a more restricted part for work-in-progress. Depending on their credentials, users should be able to use this platform at different levels of authorization, ranging from the right to have a look, the right to use and download information, up to the possibility to upload and emend information. In the end, the results may be published as 'traditional', hard copy FM instalments. The Board of the Flora Malesiana Foundation, with representatives from all leading institutes could take on this front-desk function, to stimulate that FM really becomes an online environment, as an enterprise of ongoing revision work.

An important point also to be considered is the concern for career perspectives. We urgently need to develop a widely accepted system of credits for such web-based taxonomic output, to be incorporated in the academic quality assessments as an addition to current evaluation schemes that are exclusively dictated by the Thompson-Reuters SCl-database.

Lastly, closely linked to this point is also the concern over intellectual property rights that arises when we are not at first aiming at fixed publications, but when a major part of the project output is in the form of dynamic databases.

In the 2007 meeting, the second one in Leiden, the diversity of topics and the variety of different approaches illustrated how this 


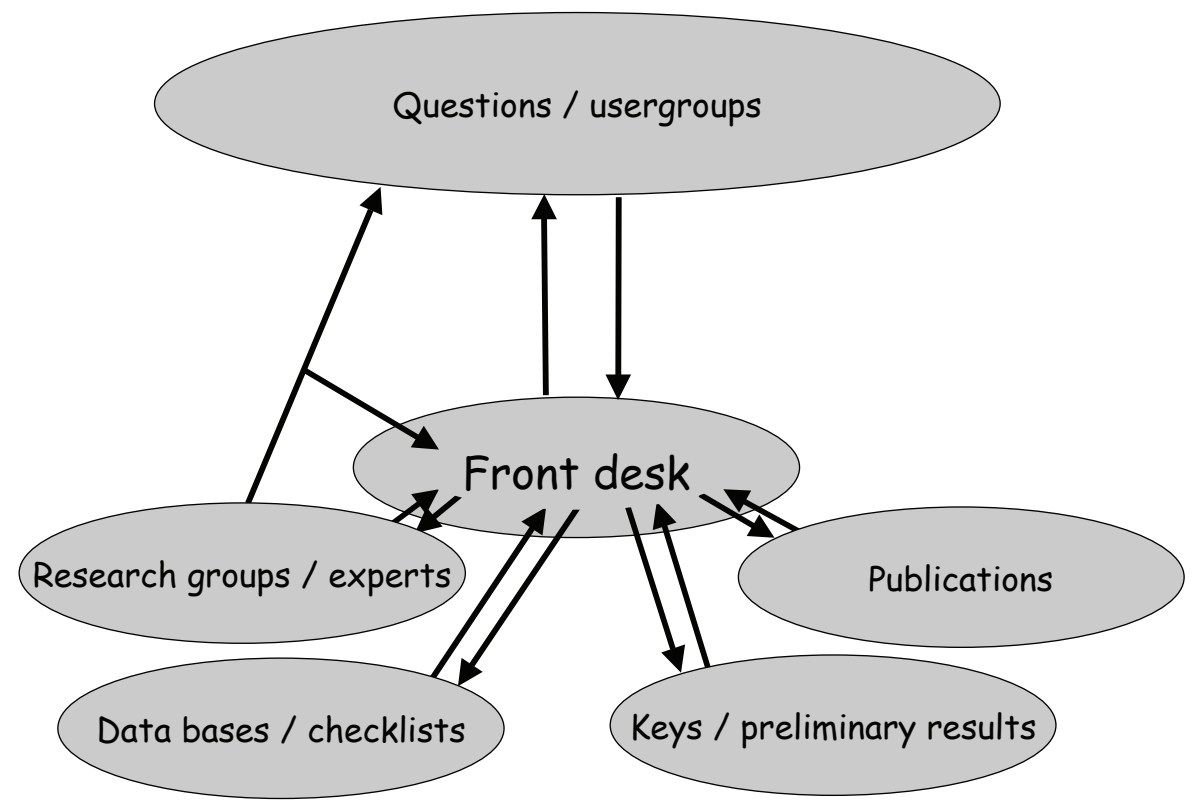

Fig. 4 Diagram showing the central function of the proposed front desk/clearing house and the lines of communication and access to information bases.

view of Flora Malesiana is becoming a reality. It is not a dusty Flora, sitting unread on bookshelves of a dwindling number of systematists. It is a vibrant community of researchers, using a wide range of classic and modern techniques, pursuing an array of taxonomic, phylogenetic, ecological, ethnobotanical, or conservation objectives, but united by a common interest in the flora and vegetation of this fascinating region. 